\title{
Controlled Release of Metformin Hydrogen Chloride from Stimuli-responsive Hydrogel based on Poly(N- Isopropylacrylamide)/Chitosan/Polyvinyl Alcohol Composite
}

\author{
Dhena Ria Barleany ${ }^{1 *}$, Claudia Vivi Ananta ${ }^{1}$, Fistia Maulina ${ }^{1}$, Agus Rochmat ${ }^{1}$, Hafid Alwan ${ }^{1}$, \\ Erizal $^{2}$ \\ ${ }^{1}$ Departement of Chemical Engineering, Faculty of Engineering, University of Sultan Ageng Tirtayasa, Jl. Jend. \\ Sudirman Km. 03, Cilegon, Banten 42435, Indonesia \\ ${ }^{2}$ Centre for Application of Isotopes and Radiation, South Jakarta 7002, Indonesia
}

\begin{abstract}
Hydrogels are ideal biomaterials owing to their unique network structure that facilitates considerable hydrophilicity and biocompatibility. At the same time, hydrogels also possess soft physical properties when combined with living tissue. In this study, metformin hydrogen chloride (metformin $\mathrm{HCl}$ )-loaded stimuli-responsive poly( $\mathrm{N}$-isopropylacrylamide) (pNIPAAm) -chitosanpolyvinyl alcohol (PVA) hydrogels were synthesized through a freezing and thawing procedure and subsequently subjected to gamma irradiation at room temperature. The gel content and the water absorption capacity of the synthesized hydrogels were analyzed. The polymer interaction in the matrix was observed by Fourier transform infrared spectroscopy, and the release of metformin $\mathrm{HCl}$ was studied in different $\mathrm{pHs}$ and temperatures. The hydrogels had $85 \%$ of the gel content and $373 \%$ of the water absorption capacity after $24 \mathrm{~h}$ of water immersion. The metformin HCl-loaded (pNIPAAm-chitosan-PVA) hydrogels demonstrated a sustained drug release profile over $7 \mathrm{~h}$. The drug release exhibited $\mathrm{pH}$-dependent and temperature-dependent behavior. The developed hydrogels showed good metformin $\mathrm{HCl}$ release ability at $\mathrm{pH} 3$ and $\mathrm{pH} 6.86$ at the temperature of $37 \circ$. The results showed that pNIPAAm-chitosan-PVA hydrogels could be employed for controlled drug release of metformin $\mathrm{HCl}$.
\end{abstract}

Keywords: Controlled drug release; Hydrogel; Metformin $\mathrm{HCl}$

\section{Introduction}

Diabetes mellitus is a disorder that can cause morbidity and mortality. It is considered a serious disease in countries across the world. It can increase susceptibility to infections and reduce life expectancy (Chacko, 2016). Metformin hydrogen chloride (metformin $\mathrm{HCl}$ ) is one of the most commonly used drugs to manage some forms of diabetes mellitus. It acts as an antihyperglycemic agent for the treatment of insulin-resistant diabetes mellitus (Zhou et al., 2018). Metformin release kinetics have been reported to have slow and incomplete absorption (bioavailability 50\%-60\%); approximately $30 \%$ to $50 \%$ of an oral dose is excreted unchanged in urine within $24 \mathrm{~h}$, and about $30 \%$ is excreted in feces (PatiñoHerrera et al., 2019). Some of the symptoms that are often reported as the side effects of metformin $\mathrm{HCl}$ in the treatment of diabetes are mostly related to the gastrointestinal digestive tract, such as diarrhea, nausea, dyspepsia, flatulence, and abdominal pain 
(Zhou et al., 2018). To increase adherence and reduce the side effects, metformin formulations in a controlled drug system have been developed (Patiño-Herrera et al., 2019; Shariatinia and Zahraee, 2017).

Drug delivery systems can increase the therapeutic effect of the drug at the target site by protecting the drug under physiological conditions, controlling its release, increasing or reducing its systemic circulation, and helping it reach the site of action (Khors et al., 2019). For these purposes, drugs are encapsulated in responsive materials that release their drug payloads under varying external triggers, such as $\mathrm{pH}$, temperature, enzymes, reduction, diol moieties, reactive oxygen species, shear stress, ionic strength, and light (Fu et al., 2018).

Natural polymers are potential candidates to form hydrogels for drug delivery applications because of their biodegradability, high biocompatibility, and low toxicity. Among natural polymers, chitosan has recently attracted growing consideration (Usman et al., 2018) owing to its cationic nature and the presence of primary amino groups in its structure, which are responsible for its many useful properties. It also possesses $\mathrm{pH}-$ and temperature-responsive properties. These responsive properties of chitosan have led to it becoming an advanced biopolymer in the development of smart polymeric systems for delivery of numerous drugs (Muharam et al., 2015; Hasnain and Nayak, 2018; Krisanti et al., 2019). Chitosan can be modified with other substances to broaden the scope of its role as a drug carrier (Kusrini et al., 2014; Shariatinia and Zahraee, 2017).

Chitosan is a unique cationic polysaccharide that can be easily functionalized into different derivatives through chemical, radiation, and enzymatic procedures (Mittal et al., 2018). Chitosan can be used as a protective material for active substances (Usman et al., 2018). An emerging technique to improve its performance and expand its potential applications uses chemical modification to graft it to a vinyl monomer(s) and then crosslink the material. For enhancing chitosan's performance, one of the more intensively studied monomers is poly(N-isopropylacrylamide) (pNIPAAm) (Zhang et al., 2009; Carreira et al., 2010; Rasib et al., 2018). pNIPAAm is one of the most studied thermally-sensitive (thermoresponsive) polymers. It has a low critical solution temperature (LCST) of $32^{\circ} \mathrm{C}$, which is a useful temperature for biomedical applications since it is close to body temperature (Carreira et al., 2010). Grafting pNIPPAm onto chitosan enables an increase in the water content of the graft following exposure to aqueous media along with improved mechanical and temperature-responsive properties (Zhang et al., 2009).

Polyvinyl alcohol (PVA) is a water-soluble synthetic polymer that has several desirable physical properties, such as elasticity and high hydrophilicity. It is cheap, non-toxic, and non-carcinogenic. It has good biocompatibility and a high degree of swelling in aqueous solutions, which make it suitable for blending with chitosan in order to produce biodegradable blend hydrogels for controlled drug release systems (Abdel-Mohsen et al., 2011).

In this article, we report a model drug delivery system for the release of metformin $\mathrm{HCl}$ based on cross-linked PVA-chitosan blended hydrogels and pNIPAAm. We used metformin $\mathrm{HCl}$ as the drug because it is a type 2 diabetes drug that needs a controlled delivery system to ensure that the release occurs at the target site. The hydrogels were prepared through a procedure that combined physical freezing-thawing and gamma-ray irradiation. The release behaviors of metformin $\mathrm{HCl}$ from the hydrogel matrix at various $\mathrm{pHs}$ and temperatures were investigated. The use of the freezing-thawing method followed by gamma irradiation produced hydrogels with good mechanical properties, compact network structures, high porosity, and high absorption capacity without any hazardous initiators or cross-linking agents (Hamedi et al., 2018). 


\section{Methods}

This research was carried out in several stages, namely the preparation of raw materials, synthesis of hydrogels, product analysis, and drug release tests using metformin $\mathrm{HCl}$ as a model drug. The hydrogel synthesis stage involved freezing and thawing followed by gamma irradiation at a total dose of $20 \mathrm{kGy}$. The hydrogel products were then tested for the release of metformin $\mathrm{HCl}$ with varying $\mathrm{pHs}$ and temperatures of the media. Several predictions and hypotheses arise from our study. The first prediction is that pNIPAAmchitosan-PVA hydrogels with high gel fraction and swelling capacity can be produced. The second prediction is that the release of metformin $\mathrm{HCl}$ from the hydrogel matrix will be affected by the $\mathrm{pH}$ and temperature of the media. This $\mathrm{pH}$ - and temperature-dependent rate of release of metformin $\mathrm{HCl}$ will be important for its application in oral therapy for the treatment of type 2 diabetes.

\subsection{Materials}

We obtained pharmaceutical grade chitosan with deacetylation degree of $85 \%$ (PT. Biotech Surindo, Cirebon, West Java, Indonesia), metformin $\mathrm{HCl}$ (DSM Anti-Infectives India Limited, India), pNIPAAm (PT. Merck Indonesia Tbk, Jakarta, Indonesia), and PVA (PT. Merck Indonesia Tbk, Jakarta, Indonesia). For the release study of metformin $\mathrm{HCl}$, buffer solutions were used (pHs 3, 6.86, and 9). Distilled water was used throughout the experiment.

\subsection{Hydrogel Preparation}

$1 \mathrm{~g}$ of chitosan was placed into a $250 \mathrm{~mL}$ glass beaker. Then, $50 \mathrm{~mL}$ of $1 \%(\mathrm{v} / \mathrm{v})$ aqueous acetic acid solution was poured into the beaker and followed with continuous stirring to obtain homogenous $2 \%(\mathrm{w} / \mathrm{v})$ chitosan solution. In a separate container, $10 \mathrm{~g}$ of PVA powder was placed into a $100 \mathrm{~mL}$ covered bottle. Then, $100 \mathrm{~mL}$ of distilled water was added to obtain $10 \%(\mathrm{w} / \mathrm{v})$ of PVA solution. The bottle was placed in an autoclave and heated at $121^{\circ} \mathrm{C}$ for $20 \mathrm{~min}$. Then, the bottle was removed from the autoclave and allowed to reach room temperature. In a $100 \mathrm{~mL}$ glass beaker glass, $2.5 \mathrm{~g}$ of pNIPAAm was placed, and $50 \mathrm{~mL}$ of chitosan solution was added followed by continuous stirring to obtain $5 \%(\mathrm{w} / \mathrm{v})$ pNIPAAm solution. The solution mixture was homogenized by using a stirrer under room conditions. A total of $3 \mathrm{~mL}$ of the solution mixtures was introduced into vials of $3 \mathrm{~mL}$ capacity ( $20 \mathrm{~mm}$ and $30 \mathrm{~mm}$ in diameter). The next step was freezing and thawing, which was conducted by putting the solution mixture in a freezer for $16 \mathrm{~h}$ and then putting it out at room temperature for $8 \mathrm{~h}$ for one cycle. Next, it was subjected to gamma-ray irradiation in an irradiator at room temperature for $4 \mathrm{~h}$ to reach $20 \mathrm{kGy}$ total dose (constant radiation rate of $5 \mathrm{kGy} / \mathrm{h}$ ). A similiar method was performed for the experiment of loading metformin $\mathrm{HCl} 30 \mathrm{mg}$ in the hydrogel material. The hydrogel resulting from the irradiation process was removed from the bottle and characterized. The release behavior of metformin $\mathrm{HCl}$ from the hydrogel matrix at various pHs and temperatures was investigated.

\subsection{Determination of Metformin HCl Maximum Absorption Wavelength}

Ten mg of metformin $\mathrm{HCl}$ was dissolved into $500 \mathrm{~mL}$ distilled water. Then, $5 \mathrm{~mL}$ of the solution was pipetted and put in a cuvette to check its absorbance at a wavelength of 200$400 \mathrm{~nm}$.

\subsection{Metformin HCl Release Study}

The drug-containing hydrogel was immersed in $100 \mathrm{~mL}$ buffer solution of pHs 3, 6.86, and 9 at the temperatures of $35^{\circ} \mathrm{C}, 37^{\circ} \mathrm{C}$, and $40^{\circ} \mathrm{C}$, and then, they were together placed into an incubator shaker tool with $10 \mathrm{rpm}$ speed. The concentration of metformin $\mathrm{HCl}$ released from the hydrogel was observed for 1-7 h. At each one-hour interval, $10 \mathrm{~mL}$ of the solution 
sample was pipetted. Distilled water was then added to the $\mathrm{pH}$ buffer solution at the same volume as the previous volume. Then, the materials were again placed back into the incubator shaker. The concentration was measured by UV-VIS spectrophotometry at maximum absorption wavelength.

\subsection{Gel Fraction Analysis}

The hydrogels of size $1 \times 1 \mathrm{~cm}$ resulting from $20 \mathrm{kGy}$ of irradiation were dried in an oven at $60^{\circ} \mathrm{C}$ to constant weight and then weighed $\left(\mathrm{W}_{0}\right)$. Dried hydrogels were then immersed in distilled water for $24 \mathrm{~h}$ to remove the unreacted pNIPAAm-PVA-chitosan. The hydrogels were then wiped with filter paper and weighed $\left(\mathrm{W}_{1}\right)$. The gel fraction was calculated according to the following equation:

$$
\text { Gel fraction }(\%)=\frac{W 1}{W 0} \times 100 \% \text {, }
$$

where $W_{1}$ is the hydrogel weight after immersing (g), and $W_{0}$ is the hydrogel weight before immersing (g).

\subsection{Water Absorption Analysis}

The hydrogel samples of size $1 \times 1 \mathrm{~cm}$ obtained after the irradiation process were dried at $60^{\circ} \mathrm{C}$ in the oven and weighed $\left(\mathrm{W}_{\mathrm{a}}\right)$ and then immersed in distilled water at room temperature. Hydrogels were taken every hour, dried with filter paper, and then weighed $\left(\mathrm{W}_{\mathrm{b}}\right)$. The same treatment was performed each hour until $24 \mathrm{~h}$. The swelling capacity of the hydrogel was determined by the following equation:

$$
\text { Swelling capacity }(\%)=\frac{w b-w a}{w a} \times 100 \%,
$$

where $W_{a}$ is the hydrogel weight in dry condition (g), and $W_{b}$ is the hydrogel weight in wet condition $(\mathrm{g})$

\subsection{Cumulative Drug Release Percentage}

The percentage of cumulative drug release from the hydrogel was calculated by the following formulas:

$$
\text { Initial mass of sample }=\left(\left(\frac{A-a}{b}\right): 1000\right)
$$

Mass at initial volume $=$ Initial mass of sample $\mathrm{x}$ Initial volume

$$
\text { Drug release }(\%)=\frac{\text { mass at initial volume }}{\text { mass of drug }} \times 100 \% \text {, }
$$

where $A$ is the percentage of absorbance, $a$ is the intercept, and $b$ is the slope.

$$
\text { Cumulative drug release }(\%)=\text { Drug release in } t_{n-1}(\%)+\text { Drug release in } t_{n}(\%)
$$

where $t_{n-1}$ is the previous time, and $t_{n}$ is the next hour

\subsection{Fourier Transform Infrared Analysis (FTIR)}

The hydrogel was crushed and mixed with fine powder of dried potassium bromide and then tested by using a Shimadzu Prestige 21 FTIR Spectrophotometer (Shimadzu Corp, Kyoto, Japan).

\section{Results and Discussion}

The reactant mixture containing pNIPAAm, PVA, and chitosan in liquid form was transformed into a gel after the irradiation process. The change in the shape of the material mixture before and after irradiation is shown in Figure 1. 


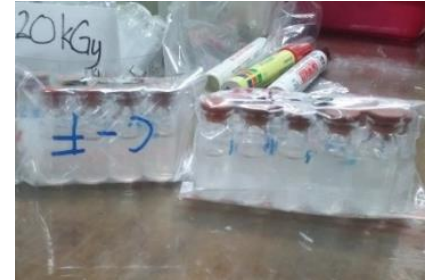

(a)

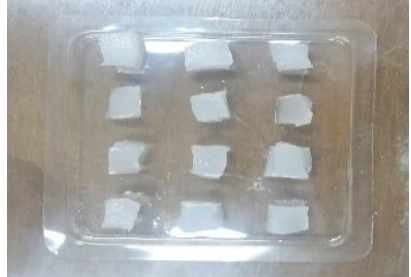

(b)

Figure 1 Change in the material's shape during the preparation: (a) Before irradiation; (b) Hydrogels of (pNIPAAm-chitosan-PVA) that have been cut after irradiation

The combination of chitosan with synthetic or other natural polymers forms semiinterpenetrating networks (IPNs). The mechanism of IPN and semi-IPN formation has been explained (Carreira et al., 2010). Based on the literature, it can be predicted that in the process of freezing-thawing and irradiation of pNIPAAm-chitosan-PVA polymer mixture, the radiation-sensitive PVA will form cross bonds first, and the easily degraded pNIPAAm and chitosan will enter into (penetration) the structure of the PVA network. According to Afshari et al. (2015), the freezing-thawing process can also cause physical cross bonds in the PVA solution. The combination of the freeze-thawing method with irradiation produces hydrogels with better mechanical properties compared with those samples prepared by irradiation.

\subsection{FTIR Analysis}

The functional group of the hydrogel product was compared to the raw materials (chitosan, pNIPAAm, and PVA) using an FTIR spectrophotometer. The FTIR spectra of chitosan powder, pNIPAAm, PVA, and the hydrogel product are presented in Figure 2.

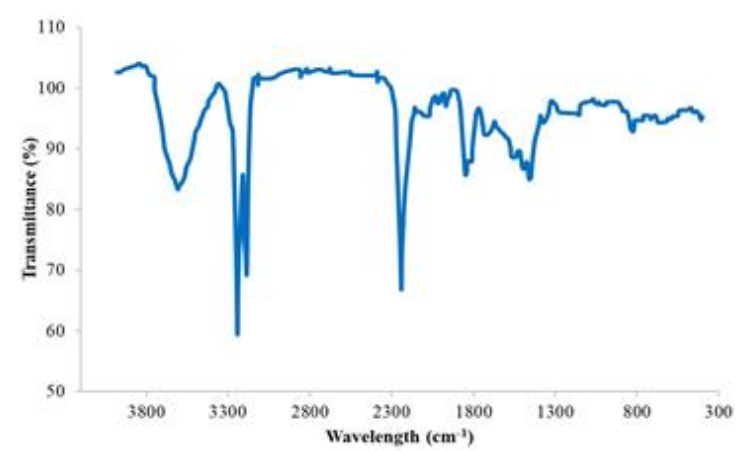

(a)

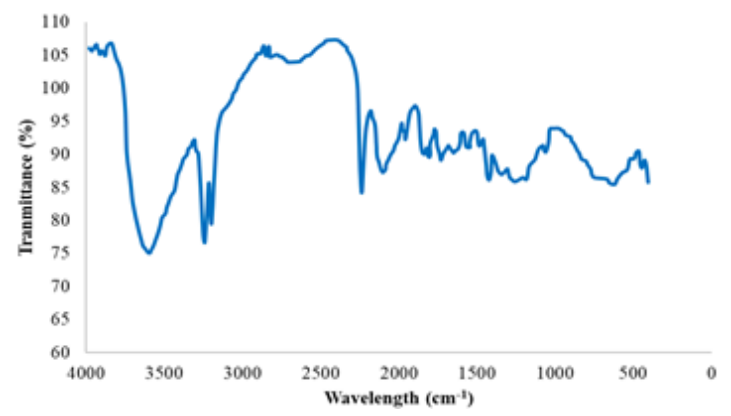

(c)

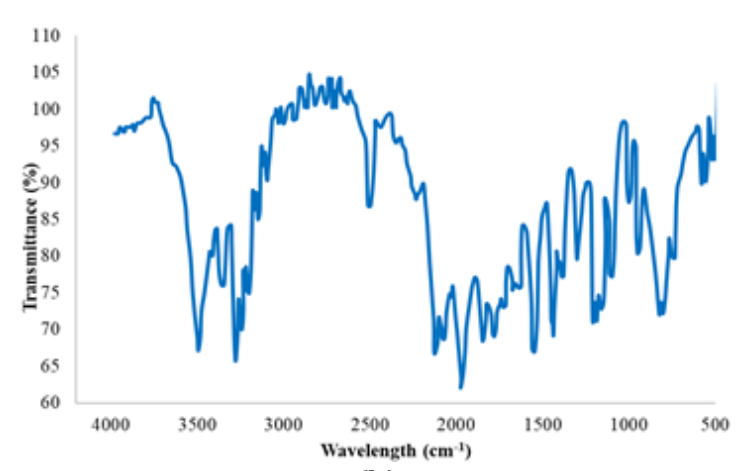

(b)

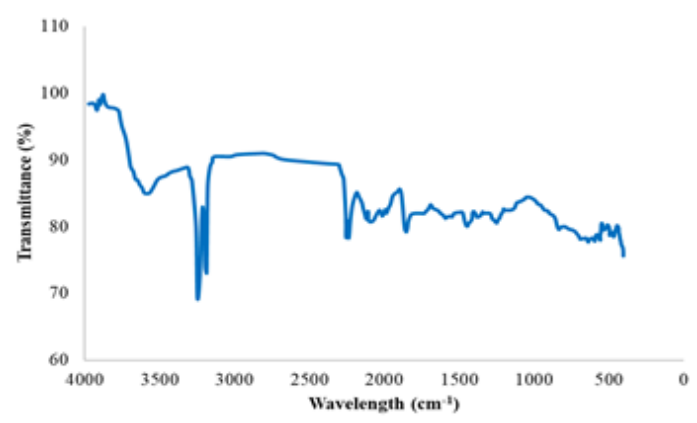

(d)

Figure 2 FTIR spectra: (a) PVA; (b) pNIPAAm; (c) Chitosan; and (d) pNIPAAm-Chitosan-PVA hydrogel 
In Figure 2a, it can be seen that the OH group of the PVA has a wide absorption peak at the wavelength of $3621 \mathrm{~cm}^{-1}$ from the intramolecular and intermolecular hydrogen bonds; the $\mathrm{CH}$ groups are observed at wavelengths 3241 and $3185 \mathrm{~cm}^{-1}$, each associated with symmetrical stretching vibrations and the asymmetry of $\mathrm{C}-\mathrm{H}$ alkyl groups; and the $\mathrm{C}=\mathrm{O}$ group is observed at the wavelength of $1850 \mathrm{~cm}^{-1}$ (Awada and Daneault, 2015). In Figure $2 \mathrm{~b}$, for pNIPAAm, it seems that the NH group vibration appears at the wavelength of 3492 $\mathrm{cm}^{-1}$, the stretching vibration of the $-\mathrm{C}=\mathrm{C}$ appears at wavelengths of 1560 and $1436 \mathrm{~cm}^{-1}$, the strain $\mathrm{CH}$ is verified at $3276 \mathrm{~cm}^{-1}$, the $\mathrm{CH}$ vibration occurs at the wavelength of $1380 \mathrm{~cm}^{-}$ 1 , the stretching vibration of the carbonyl $\mathrm{C}=0$ appears at the wavelength of $1788 \mathrm{~cm}^{-1}$, and the CN group is observed at the wavelength of $1097 \mathrm{~cm}^{-1}$ (Seddiki and Aliouche, 2013; Wang et al., 2015). Figure 2c shows the chitosan functional groups, where the $\mathrm{OH}$ and $\mathrm{NH}$ functional groups have strong absorption peaks at the wavelength of $3423.65 \mathrm{~cm}^{-1}$, the symmetrical stretching adsorption and $\mathrm{CH}$ asymmetry group appear at wavelengths of $3240 \mathrm{~cm}^{-1}$ and $3196 \mathrm{~cm}^{-1}$, the $\mathrm{N}$-acetyl group residues are confirmed the wavelength of $1673 \mathrm{~cm}^{-1}$ (the stretching pattern adsorbs $\mathrm{C}=0$ on amides) and the $1435 \mathrm{~cm}^{-1}$ uptake (the CN strain on the amide group pattern), and the absorption band of $1102 \mathrm{~cm}^{-1}$ can be suspected as the stretching asymmetry of the C-O-C group (Queiroz et al., 2015). The pNIPAAm-chitosan-PVA hydrogel spectrum is shown in Figure 2(d), which represents the combination of the peaks of the three ingredients. The $\mathrm{OH}$ and $\mathrm{NH}$ functional groups have absorption peaks at the wavelength of $3609 \mathrm{~cm}^{-1}$, the symmetry stretching adsorption and the $\mathrm{CH}$ asymmetry group appear at wavelengths of $3247 \mathrm{~cm}^{-1}$ and $3195 \mathrm{~cm}^{-1}$, the $\mathrm{C}=0$ group is seen at the wavelength of $1863 \mathrm{~cm}^{-1}$, the CO group is observed at the wavelength of 1174 $\mathrm{cm}^{-1}$, and the CN group is seen at the wavelength of $1278 \mathrm{~cm}^{-1}$.

\subsection{Gel Fraction and Water Absorption Analysis}

In this study, hydrogel products were made three times with a constant dose of gammaray irradiation of dose $20 \mathrm{kGy}$. The three products were then analyzed for their gel fraction and their ability to absorb water.

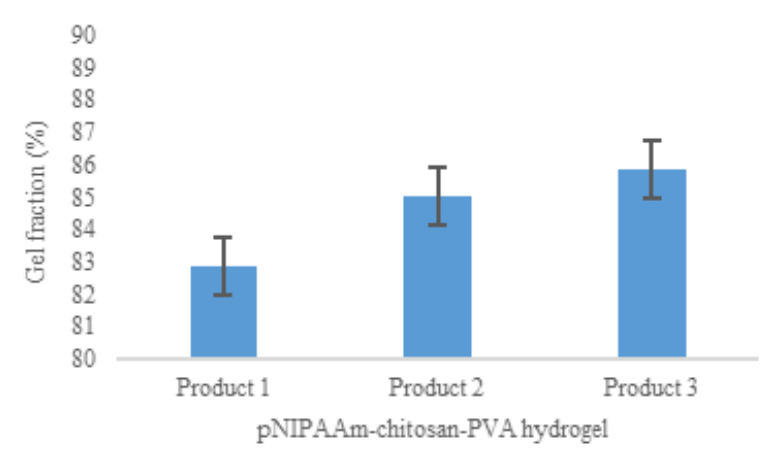

(a)

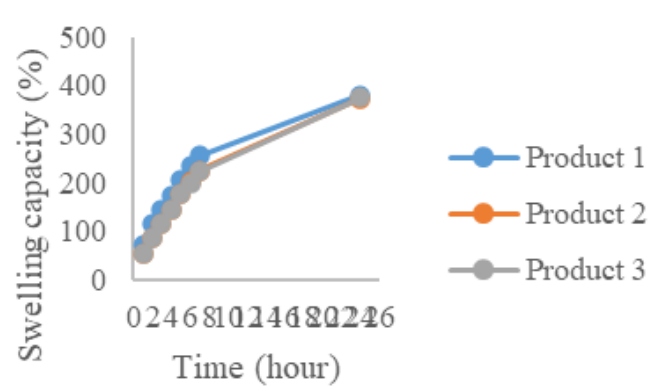

(b)

Figure 3 Physical properties of the hydrogel product: (a) Gel fraction; (b) Swelling

Figure 3a shows the gel fraction values of three hydrogel products after identical irradiation. Product 1 has the gel fraction value of $82.88 \%$, product 2 has the gel fraction value of $85.03 \%$, and product 3 has the gel fraction value of $85.86 \%$. The gel fraction indicates the number of cross-links that occur between the polymers in the hydrogel (Alcântara et al., 2012). The higher the density of cross-links formed, the lower the swelling capacity of the hydrogel. Therefore, the ability of water to enter and exit the hydrogel is reduced. In this way, the drug release process can be controlled. The relationship between 
the swelling ability of the pNIPAAm-chitosan-PVA hydrogel and the immersion time is shown in Figure 3b.

The hydrogel has a cross-link that will form a three-dimensional macromolecular network with the ability to absorb water that is far beyond its own weight or volume (commonly referred to as superabsorbent material). The hydrogel is insoluble in water. In the mechanism of water absorption by hydrogels, the hydrophilic group of the polymer plays an important role. When the polymer is immersed in water, a reaction occurs with hydrogen atoms that releases positive ions. This results in negative charges along the repelling polymer chain, which forces the polymer chain to open and bind water with hydrogen bonds (Kalhapure et al., 2016). There is also an increase in the hydrogel porosity as water diffuses into the hydrogel pores (Erizal et al., 2015).

Hydrogels can generally absorb water that is more than 400 times their weight (Kalhapure et al., 2016). In this study, the water absorption value of the pNIPAAmchitosan-PVA hydrogel was 373\% (373 times its own dry weight).

\subsection{Metformin HCl Release Study}

The result of the maximum wavelength measurement for metformin $\mathrm{HCl}$ is shown in Figure 4a. Accordingly, the analysis of metformin $\mathrm{HCl}$ concentration release from the hydrogel matrix was carried out at the wavelength of $230 \mathrm{~nm}$.

The metformin $\mathrm{HCl}$ release analysis was used to determine the cumulative amount of drug that was released from the hydrogel matrix. The results from the release of $30 \mathrm{mg}$ of metformin $\mathrm{HCl}$ from the hydrogel at pHs 3, 6.86, and 9 at temperatures of $35^{\circ} \mathrm{C}, 37^{\circ} \mathrm{C}$, and $40^{\circ} \mathrm{C}$, respectively, are shown in Figures $4 \mathrm{~b}, 4 \mathrm{c}, 4 \mathrm{~d}$. The metformin $\mathrm{HCl}$ drug release test was carried out for up to $7 \mathrm{~h}$ to conform to the standards of the U.S. Pharmacopeial Convention 2018 (The United States Pharmacopeial Convention, 2018), in which on average the release was carried out for 1 to $10 \mathrm{~h}$ to test the dissolution amount of metformin HCl tablets.

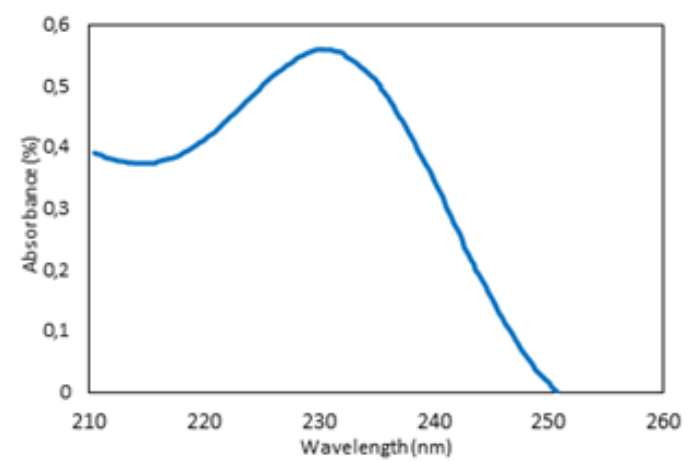

(a)

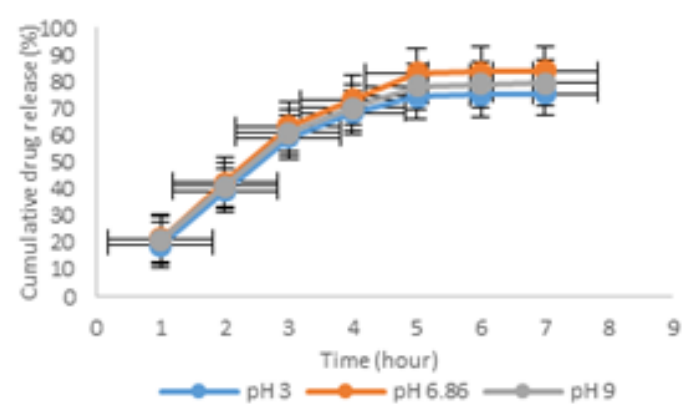

(c)

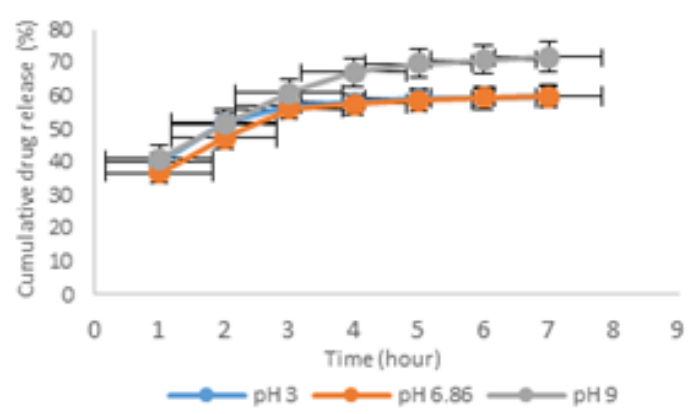

(b)

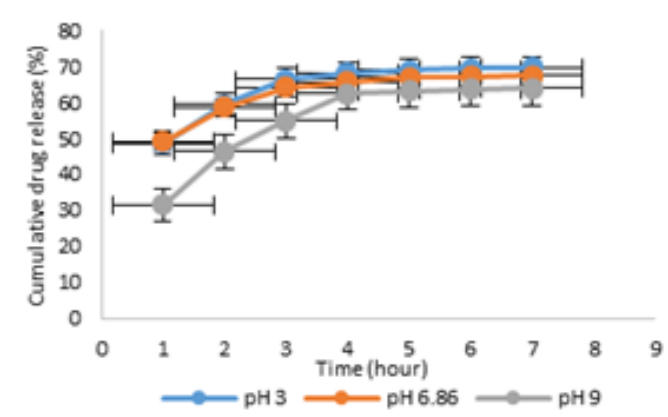

(d)

Figure 4 Cumulative release of metformin $\mathrm{HCl}$ : (a) Maximum absorbance of metformin $\mathrm{HCl}$ using UV-Vis spectrophotometry. Relation between time and cumulative release of metformin $\mathrm{HCl}$ at different temperatures: (b) $35^{\circ} \mathrm{C}$; (c) $37^{\circ} \mathrm{C}$; and (d) $40^{\circ} \mathrm{C}$ 
As can be seen in Figures $4 \mathrm{~b}, 4 \mathrm{c}$, and $4 \mathrm{~d}$, the release profiles of all conditions show that the cumulative release first increases with time and then becomes almost constant up to 7 h. This is an appropriate pattern for a controlled drug release, as it is a way to achieve a fixed plasma drug concentration at all times. The drug is delivered continuously at a predetermined rate for the long term (Kakar et al., 2014).

High release values of metformin $\mathrm{HCl}$ were found at $35^{\circ} \mathrm{C}(36-40 \%)$ at $\mathrm{pH} 6.86$ and $40^{\circ} \mathrm{C}(31-49 \%)$ at $\mathrm{pH} 9$ in the first hour. At $37^{\circ} \mathrm{C}$, the release was in the range of $19-21 \%$ for all pH levels. This pattern is known as the burst effect, which is an uncontrolled release of the drug from the surface of the hydrogel because of the $\mathrm{pH}$-responsive polymer particle size (Rizi et al., 2011). High release of the drug in the initial hours was also observed in an in vitro drug release study of metformin encapsulated in chitosan matrices (Ghazaie et al., 2017). The study reported that the metformin-chitosan composite without any additional coating released almost all of the drug in $5 \mathrm{~h}$. Other studies found different burst release profiles and sustained release periods depending on several factors, including the composition of the composite material used as a drug carrier, the particle size, $\mathrm{pH}$, and temperature.

\subsubsection{Effect of temperature on drug release}

Increase of temperature results in an increase of diffusion of drug molecules when immersed in an extracting medium (Lin et al., 2003). Consistent with this, it can be seen in Figures $4 \mathrm{~b}, 4 \mathrm{c}$, and $4 \mathrm{~d}$ that there was an increase in the rates of metformin $\mathrm{HCl}$ release from the hydrogel at $37^{\circ} \mathrm{C}$ and $40^{\circ} \mathrm{C}$ relative to the rate at $35^{\circ} \mathrm{C}$, especially at pH 3 and pH 6.86 . As body temperature can change because of fever, local infection, or disease, this characteristic is advantageous for the design of controlled drug delivery systems (Carreira et al., 2010).

In the first two hours, the released metformin $\mathrm{HCl}$ ranged from $39 \%-60 \%$; in the fourth hour, it ranged from 57\%-74\%; and at the sixth hour, it ranged from 59\%-84\%. The release behavior of metformin $\mathrm{HCl}$ from the hydrogel in this study shows that this system was temperature-responsive, and $37^{\circ} \mathrm{C}$ is the temperature that gives the best curve compared with the standard from USP Convention 2018.

\subsubsection{Effect of $\mathrm{pH}$ on drug release}

The $\mathrm{pH}$ in the gastrointestinal tract varies from $\sim 1.5$ to 4 in the stomach and $\sim 7$ to 8.5 in the small intestine (Shariatinia and Zahraee, 2017). For the oral administration of a drug intended for intestinal release, the coating material must hold the drug temporarily in the stomach (acidic $\mathrm{pH}$ ) and release it once in the intestine (neutral pH) (Carreira et al., 2010).

In the three temperature variations studied, it appears that a temperature of $37^{\circ} \mathrm{C}$ provides a profile that is in line with expectations. At this temperature, the amount of metformin $\mathrm{HCl}$ released at acidic condition is lower than that at the $\mathrm{pH}$ of neutral and alkaline media. At pH 3, the hydrogel matrix releases $19.42 \%$ of the drug in the first hour, and the cumulative released amount reaches $75.67 \%$ in the seventh hour; at pH 6.86, the cumulative drug release is equal to $21.67 \%$ in the first hour and $84.27 \%$ in the seventh hour; and at $\mathrm{pH} 9$, the cumulative drug release is $21.22 \%$ in the first hour and $79.35 \%$ in the seventh hour. This data shows that the pNIPAAm-chitosan-PVA hydrogel produced in this study is suitable for the release of metformin $\mathrm{HCl}$ under acidic (stomach) conditions, which is usually faster than neutral or alkaline (intestine) conditions.

\section{Conclusions}

From this study, it can be concluded that a pH- and temperature-responsive pNIPAAmchitosan-PVA hydrogel can be synthesized through a combination of physical and chemical 
crosslinking by freezing and thawing followed by gamma irradiation. A dose of $20 \mathrm{kGy}$ gamma-ray irradiation can produce a hydrogel with a gel fraction of $85 \%$ and water absorption capacity of $373 \%$ after $24 \mathrm{~h}$ of immersion. The developed hydrogels showed good metformin $\mathrm{HCl}$ release ability at the temperature of $37^{\circ} \mathrm{C}$. The results showed that pNIPAAm-chitosan-PVA hydrogel hydrogels could be employed for controlled drug release of metformin $\mathrm{HCl}$.

\section{Acknowledgements}

We highly appreciate the financial support from the University of Sultan Ageng Tirtayasa (UNTIRTA) through the "Competency Based Research Grant Program" for fiscal year 2018 (contract number: 667/UN43.9/PP/KT/2018).

\section{References}

Abdel-Mohsen, A.M., Aly, A.S., Hrdina, R., Montaser, A.S., Hebeish, A., 2011. Eco-synthesis of PVA/Chitosan Hydrogels for Biomedical Application. Journal of Polymers and Environment, Volume 19(4), pp. 1005-1012

Afshari, M.J., Sheik, N., Afarideh, H., 2015. PVA/CM-chitosan/honey Hydrogels Prepared by using the Combined Technique of Irradiation Followed by Freezing-thawing. Radiation Physics and Chemistry, Volume 113, pp. 28-35

Alcântara, M.T.S., Brant, A.J.C., Giannini, D.R., Pessoa, J.O.C.P., Andrade, A.B., Riella, H.G., Lugão, A.B., 2012. Influence of Dissolution Processing of PVA Blends on the Characteristics of their Hydrogels Synthesized by Radiation-Part I: Gel Fraction, Swelling, and Mechanical Properties. Radiation Physics and Chemistry, Volume 81(9), pp. $1465-1470$

Awada, H., Daneault, C., 2015. Chemical Modification of Poly(Vinyl Alcohol) in Water. Applied Sciences, Volume 5(4), pp. 840-850

Carreira, A.S., Gonçalves, F.A.M.M., Mendonça, P.V., Gil, M.H., Coelho, J.F.J., 2010. Temperature and $\mathrm{pH}$ Responsive Polymers based on Chitosan: Applications and New Graft Copolymerization Strategies based on Living Radical Polymerization. Carbohydrate Polymers, Volume 80(3), pp. 618-630

Chacko, E., 2016. Blunting Post-meal Glucose Surges in People with Diabetes. World Journal Diabetes, Volume 7(11), pp. 239-242

Erizal, Abbas, B., Sukaryo, S.G., Barleany, D.R., 2015. Synthesis and Characterization Superabsorbent Hydrogels of Partially Neutralized Acrylic Acid Prepared using Gamma Irradiation: Swelling and Thermal Behavior. Indonesian Journal of Chemistry, Volume 15(3), pp. 281-287

Fu, X., Hosta-Rigau, L., Chandrawati, R., Cui, J., 2018. Multi-Stimuli-Responsive Polymer Particles, Film, and Hydrogels for Drug Delivery. Chem, Volume 4(9), pp. 2084-2107

Ghazaie, M., Ghiaci, P., Ghiaci, M. 2017. Study on Release of Naproxen and Metformin Encapsulated in Biopolymer-Inorganic Mesoporous Matrices as Controlled DrugDelivery Systems. Microporous and Mesoporous Materials, Volume 244, pp. 291-300

Hamedi, H., Moradi, S., Hudson, S.M., Tonelli, A.E. 2018. Chitosan Based Hydrogels and Their Applications for Drug Delivery in Wound Dressings: A Review. Carbohydrate Polymers, Volume 199, pp. 445-460

Hasnain, M.S., Nayak, A.K., 2018. Chitosan as Responsive Polymer for Drug Delivery Applications. Stimuli Responsive Polymeric Nanocarriers for Drug Delivery Applications, Types and Triggers, Volume 1, pp. 581-605 
Kakar, S., Singh, R., Semwal, A., 2014. Drug Release Characteristics of Dosage Form: A Review. Journal of Coastal Life Medicine, Volume 2(4), pp. 332-336

Kalhapure, A., Kumar, R., Singh, V.P., Pandey, D.S., 2016. Hydrogels: A Boon for Increasing Agricultural Productivity in Water-Stressed Environment. Current Science, Volume 3(11), pp. 1773-1779

Khors, N.J., Liyanage, T., Venkatesan, N., Najarzadeh, A., Puleo, D.A., 2019. Drug Delivery Systems and Controlled Release. Reference Module in Biological Sciences: Encyclopedia of Biomedical Engineering, pp. 316-329

Krisanti, E.A., Hijrianti, N., Mulia, K., 2019. Preparation and Evaluation of Alginate-Chitosan Matrices Loaded with Red Ginger Oleoresin using the Ionotropic Gelation Method. International Journal of Technology, Volume 10(8), pp. 1513-1522

Kusrini, E., Arbianti, R., Sofyan, N., Abdullah, M.A.A., Andriani, F., 2014. Modification of Chitosan by using Samarium for Potential use in Drug Delivery System. Spectrochimica Acta Part A: Molecular and Biomolecular Spectroscopy, Volume 120, pp. 77-83

Lin, D.M., Kalachandra, S., Valiyaparambil, J., Offenbacher S., 2003. A Polymeric Device for Delivery of Anti-Microbial and Anti-fungal Drugs in the Oral Environment: Effect of Temperature and Medium on the Rate of Drug Release. Dental Materials, Volume 19, pp. 589-596

Mittal, H., Ray, S.S., Kaith, B.S., Bhatia, J.K., Sukriti, Sharma, J., Alhassan, S.M., 2018. Recent Progress in the Structural Modification of Chitosan for Applications in Diversified Biomedical Fields. European Polymer Journal, Volume 109, pp. 402-434

Muharam, Y, Purwanto, W.W., Mulia, K., Wulan, P.P.D.K., Marzuki, I., Dewi, M.N., 2015. Mathematical Model Controlled Potassium Chloride Release Systems from Chitosan Microspheres. International Journal of Technology, Volume 6(7), pp. 1228-1237

Patiño-Herrera, R., Louvier-Hernández, J.F., Escamilla-Silva, E.M., Chaumel, J., Escobedo,

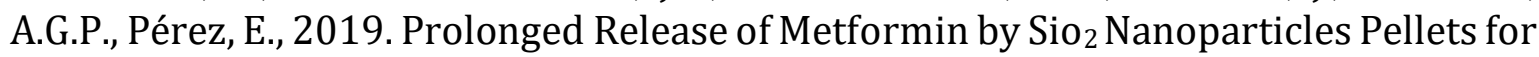
Type II Diabetes Control. European Journal of Pharmaceutical Sciences, Volume 131, pp. $1-8$

Queiroz, M.F., Melo, K.R.T., Sabry, D.A., Sassaki, G.L., Rocha, H.A.O., 2015. Does the Use of Chitosan Contribute to Oxalate Kidney Stone Formation?. Marine Drugs, Volume 13(1), pp. 141-158

Rasib, S.Z.M., Ahmad, Z., Khan, A., Akil, H.M., Othman, M.B.H., Hamid, Z.A.A., Ullah, F., 2018. Synthesis and Evaluation on pH- and Temperature-responsive Chitosan-p(MAA-coNIPAM) Hydrogels. International Journal of Biological Macromolecules, Volume 108, pp. 367-375

Rizi, K., Green, R.J., Khutoryanskaya, O., Donaldson, M., Williams, A.C., 2011. Mechanism of Burst Release from pH-responsive Polymeric Microparticles. Journal Pharmacy and Pharmacology, Volume 63(9), pp. 1141-1155

Seddiki, N., Aliouche, D., 2013. Synthesis, Rheological Behavior and Swelling Properties of Copolymer Hydrogels based on Poly(N-Isopropylacrylamide) with Hydrophilic Monomers. Bulletin of the Chemical Society of Ethiopia, Volume 27(3), pp. 447-457

Shariatinia, Z., Zahraee, Z., 2017. Controlled Release of Metformin from Chitosan-based Nanocomposite Films Containing Mesoporous MCM-41 Nanoparticles as Novel Drug Delivery Systems. Journal of Colloid and Interface Science, Volume 501, pp. 60-76

The United States Pharmacopeial Convention, 2018. Metformin Hydrochloride ExtendedRelease Tablets. USP-NF Monograph (Revision Bulletin)

Usman, A., Kusrini, E., Widiantoro, A.B., Hardiya, E., Abdullah, N.A., Yulizar, Y., 2018. Fabrication of Chitosan Nanoparticles Containing Samarium Ion Potentially Applicable 
for Fluorescence Detection and Energy Transfer. International Journal of Technology, Volume 9(6), pp. 1112-1120

Wang, L., Zhao, X., Zhang, Y., Zhang, W., Ren, T., Chen, Z., Wang, F., Yang, H., 2015. Fabrication of Intelligent Poly(N-Isopropylacrylamide)/Silver Nanoparticle Composite Films with Dynamic Surface-Enhanced Raman Scattering Effect. RSC Advances, Volume 5(50), pp. 40437-40443

Zhang, H.F., Zhong, H., Zhang, L.L., Chen, S.B., Zhao, Y.J., Zhu, Y.L., 2009. Synthesis and Characterization of Thermosensitive Graft Copolymer of N-Isopropylacrylamide with Biodegradable Carboxymethylchitosan. Carbohydrate Polymers, Volume 77(4), pp. 785-790

Zhou, T., Xu, X., Du, M., Zhao, T., Wang, J., 2018. A Preclinical Overview of Metformin for the Treatment of Type 2 Diabetes. Biomedicine and Pharmacotherapy, Volume 106, pp. 1227-1235 